\title{
Stability Analysis of Unsupported Vertical Cuts in the Vadose Zone using 2D and 3D Numerical Methods
}

\author{
Gregory Brennan ${ }^{1}$, Won-Taek $\mathrm{Oh}^{1}{ }^{*}$, and Othman Nasir ${ }^{1}$ \\ ${ }^{1}$ Department of Civil Engineering, University of New Brunswick, NB, Fredericton, Canada
}

\begin{abstract}
Evidence supporting the implementation of three-dimensional (3D) slope stability analysis in geotechnical engineering practice has been mounting since the nineteen-seventies. Current levels of computational power and its accessibility has allowed researchers to investigate the significance of the 3D numerical analysis output compared to conventional 2D limit equilibrium approach. This study compares results of stability analyses of unsupported vertical cuts in the vadose zone using both 2D (GeoStudio 2019 R2) and 3D (FLAC3D) software. Numerical analyses are carried out for various dimensions of unsupported vertical cuts excavated in an unsaturated glacial till. The findings from two different methods (i.e. 2D and 3D) and the limitations of 2D stability analysis are discussed.
\end{abstract}

\section{INTRODUCTION}

Most engineering projects involving foundations, landfills, pipelines, storm drains, etc. are initiated with an excavation or a trench prior to the installation of infrastructure. Workers are often required to enter the excavation or trench during the construction process, which may present serious risks. Excavation or trenching is inherently dangerous due to the risk of cave-ins which may result in severe injury, death, and/or consequential damage to adjacent property. Thousands of work-related deaths and injuries in the construction industry have been attributed to the collapse of excavations or trenches.

The critical height (i.e. maximum depth of an unsupported cut that can be excavated without failure) is the most important design consideration for ensuring the stability of unsupported excavations or trenches. Many construction projects involve excavation or trenching and installing infrastructure in the vadose zone; thus, the critical height of an unsupported cut should be determined by extending the mechanics of unsaturated soils. Previous studies also showed that the stability of unsupported cuts is mainly governed by the distribution of matric suction between the soil surface and the groundwater table ([1-4]). In other words, adhering to a universal safe height may not be a reasonable approach in geotechnical engineering practice (e.g. 1.2 to $1.5 \mathrm{~m}$ by Canadian provincial regulations).

The critical height of an unsupported cut in the vadose zone can be estimated by conducting a slope stability analysis while considering the influence of matric suction. In this case, two different approaches can be used; namely, 2D and 3D methods. According to Health and Safety Ontario [5], excavation is defined as a hole left in the ground as the result of removing material and a trench is an excavation in which the depth exceeds the width (Fig. 1). If the lengths of longitudinal sections for both an excavation and a trench are long enough (i.e. no influence of boundary conditions), both $2 \mathrm{D}$ and $3 \mathrm{D}$ methods can result in the same critical height. On the contrary, there can be obvious differences in the critical heights of cross-sections between an excavation and a trench from $2 \mathrm{D}$ and $3 \mathrm{D}$ methods since the width of a trench is narrower than that of excavation. Field workers intuitively know that the narrower the width of the crosssection, the higher the factor of safety. However, this can give an impression that the stability of the cross-section of an unsupported vertical cut is not of concern even if the width of a cross-section is wide enough not to be affected by $3 \mathrm{D}$ effects.

In the present study, an attempt is made to compare the critical heights of unsupported vertical cuts in an unsaturated glacial till (i.e. Indian Head till) for various dimensions of cross-sections using SLOPE/W (GeoStudio 2019, 2D method) and FLAC3D (3D method).

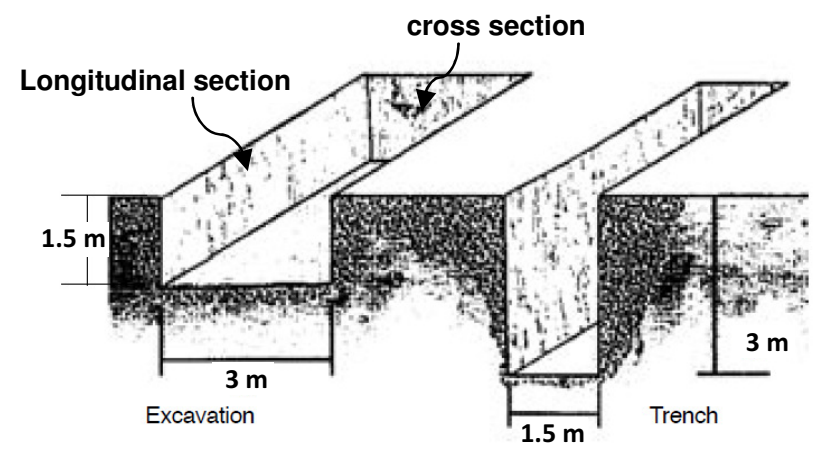

Fig. 1. Difference between excavation and trench ([5]). 


\section{SOIL PROPERTIES}

In this study, it was assumed that unsupported vertical cuts are made into a glacial till (i.e. Indian Head till) with a ground water table (GWT) at $1 \mathrm{~m}$ below the surface. Basic properties of the soil are summarized in Table 1. The grain size distribution curve of the soil is shown in Fig. 2. The water retention curve (WRC) was measured using a Tempe cell apparatus extending the axis-translation technique (Fig. 3; [6]). A best-fit analysis for the WRC was conducted using Fredlund and Xing's model [7]; the fitting parameters are summarized in Fig. 3.

Table 1. Basic soil properties of Indian Head till ([4]).

\begin{tabular}{|c|c|}
\hline Soil properties & Value \\
\hline Plasticity index, $I_{p}$ & 15.5 \\
\hline Specific gravity, $G_{s}$ & 2.7 \\
\hline Void ratio, $e$ & 0.69 \\
\hline Saturated unit weight, $\gamma_{\text {sat }}\left(\mathrm{kN} / \mathrm{m}^{3}\right)$ & 20.7 \\
\hline Effective cohesion, $c^{\prime}\left(\mathrm{kN} / \mathrm{m}^{2}\right)$ & 5 \\
\hline Friction angle, $\phi^{\prime}\left({ }^{\circ}\right)$ & 23.1 \\
\hline
\end{tabular}

The variation of the unit weight with respect to volumetric water content (or matric suction) was calculated using Eq. (1).

$$
\gamma=\frac{G_{s}+\theta(1+e)}{(1+e)} \gamma_{w}
$$

where, $\gamma=$ unit weight of soil, $G_{s}=$ specific gravity, $\theta=$ volumetric water content, $e=$ void ratio, and $\gamma_{w}=$ unit weight of water

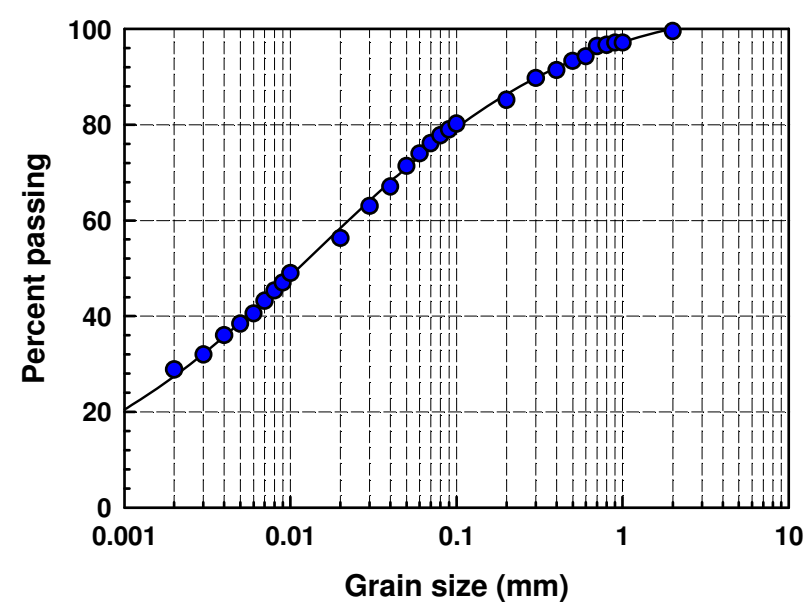

Fig. 2. Grain size distribution curve of Indian Head till.

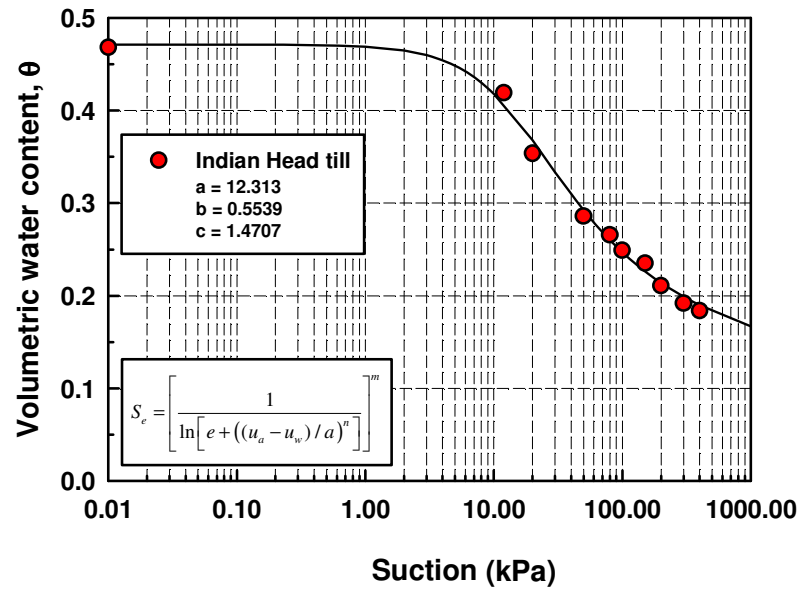

Fig. 3. WRC of Indian Head till.

\section{METHODOLOGIES AND RESULTS}

Critical heights were estimated using SLOPE/W (product of GeoStudio 2019 R2, 2D) and FLAC3D (3D) and the results were compared for a case where the GWT is $1 \mathrm{~m}$ below the ground surface. It should be noted that stability analyses were carried out without considering a drop in the phreatic line that would be associated with the excavation process. This approach presents conservative results since the increase in shear strength attributed to the excavation and subsequently generated negative pore-water pressure are neglected.

\subsection{D method}

For the 2D method, Bishop's Simplified Method was used to find a critical height with factor of safety (FOS) equal to one. For soil with negative pore-water pressure (i.e. matric suction), total cohesion was computed using Eq. (2) using effective shear strength parameters and the WRC. The residual volumetric water content was taken as $5 \%$ of the volumetric water content at saturation. The Mohr-Coulomb failure criterion was used as the material model.

$$
C=c^{\prime}+\left(u_{a}-u_{w}\right)\left(\frac{\theta-\theta_{r}}{\theta_{s}-\theta_{r}}\right) \tan \phi^{\prime}
$$

where, $c^{\prime}=$ effective cohesion, $u_{a}=$ pore-air pressure, $u_{w}=$ pore-water pressure, $\left(u_{a}-u_{w}\right)=$ matric suction, $\theta_{r}=$ residual volumetric water content, $\theta_{s}=$ volumetric water content at saturation, $\phi^{\prime}=$ friction angle.

In SLOPE/W, the shape and positions of trial slip surfaces can be defined using four different options: i) Entry and Exit, ii) Grid and Radius, iii) Block Specified, and iv) Fully Specified. Each method processes every defined slip surface to find the minimum FOS. The 'Entry and Exit' method was chosen to specify the trial slip surfaces in this study. The entry was defined as a range as wide as the excavation depth with an entry point every $10 \mathrm{~mm}$, and the toe of the vertical cut was specified as the exit point (Fig. 4). As can be seen in Fig. 
5 , the critical height from the $2 \mathrm{D}$ analysis with a GWT at $1 \mathrm{~m}$ was estimated to be $1.8 \mathrm{~m}$.

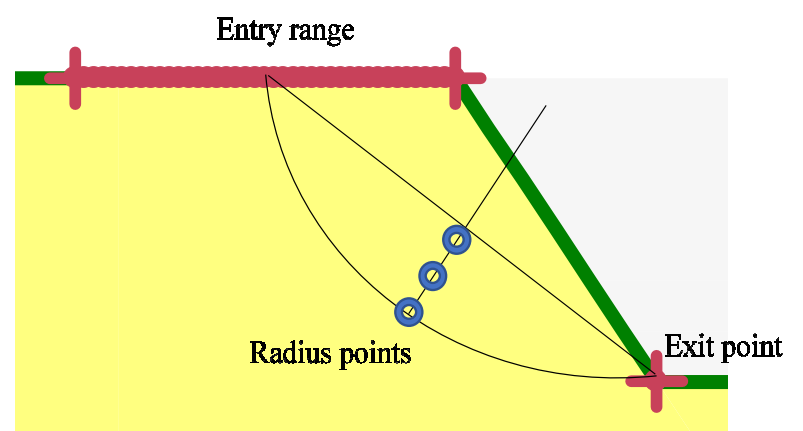

Fig. 4. Schematic of the 'Entry and Exit' slip surface method in SLOPE/W.

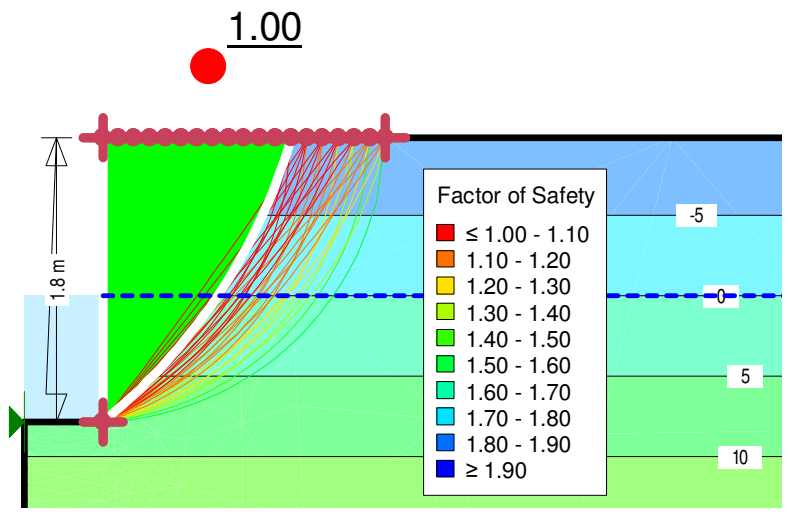

Fig. 5. Slope stability analysis in SLOPE/W (2D) using Bishop's simplified method with GWT at $1 \mathrm{~m}$.

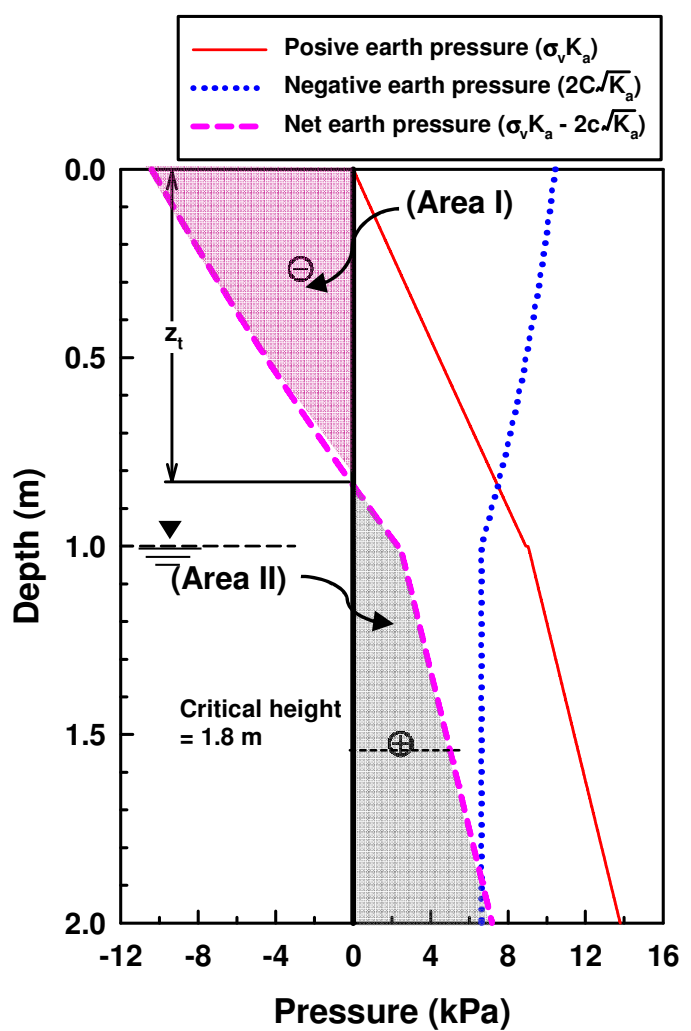

Fig. 6. Positive, negative, and net active earth pressure diagram with GWT at $1 \mathrm{~m}$.
The same result was obtained when the critical height was calculated based on the active earth pressure distribution diagram extending the approach proposed by Pufahl et al. [8] as detailed in [9] (Eq. (3); Fig. 6). The critical height can be estimated by locating the depth that equates 'Area I' and 'Area II', where the net horizontal thrust is zero as shown in Fig. 6.

$$
\begin{aligned}
& \sigma_{a}=\left[\frac{G_{s}+\theta(1+e)}{(1+e)}\right] \gamma_{w} z K_{a} \\
&-2 \sqrt{K_{a}}\left[c^{\prime}+\left(u_{a}-u_{w}\right)\left(S^{\kappa}\right) \tan \phi^{\prime}\right]
\end{aligned}
$$

where, $\sigma_{a}=$ net active earth pressure, $z=$ depth from the ground surface, $K_{a}=$ active earth pressure coefficient, $S$ $=$ degree of saturation, and $\kappa=$ fitting parameter for shear strength of unsaturated soil.

\subsection{D method}

FlAC3D was used to investigate 3D effects on the critical height. As described in Fig. 5, the critical height of the unsupported cut was $1.8 \mathrm{~m}$ using $2 \mathrm{D}$ analysis. Hence, in 3D analysis, the unsupported vertical cuts were simulated with $0.8 \mathrm{~m}$ wide and $1.8 \mathrm{~m}$ deep. The stability analyses were then performed by varying the length; namely, $0.8 \mathrm{~m}, 2 \mathrm{~m}$, and $3 \mathrm{~m}$ by keeping the width and the depth unchanged with the GWT at $1 \mathrm{~m}$. Only one quarter of the problem was simulated in the analyses considering the symmetry in the geometry (Fig. 7).

Eq. (2) is used to calculate the apparent cohesion as a function of negative pore-water pressure in the vadose zone. The apparent cohesion profile is shown in Fig. 8. FLAC3D evaluates the FOS using the strength reduction method. In other words, for each trial, the reduced cohesion (Eq. (4)) and frictional resistance (Eq. (5)) are calculated by dividing them with a trial FOS.

$$
\begin{gathered}
c^{\text {trial }}=\frac{c^{\prime}}{F O S} \\
\phi^{\text {trial }}=\arctan \left(\frac{\tan \phi^{\prime}}{F O S}\right)
\end{gathered}
$$

FLAC3D iterates the solution with a certain range of trial FOS until an accurate value of a reduction factor (i.e. FOS) to cause a failure is achieved. Fig. 9 shows an example of the slip surface created based on displacement contours with a reduction factor of 0.9 . 


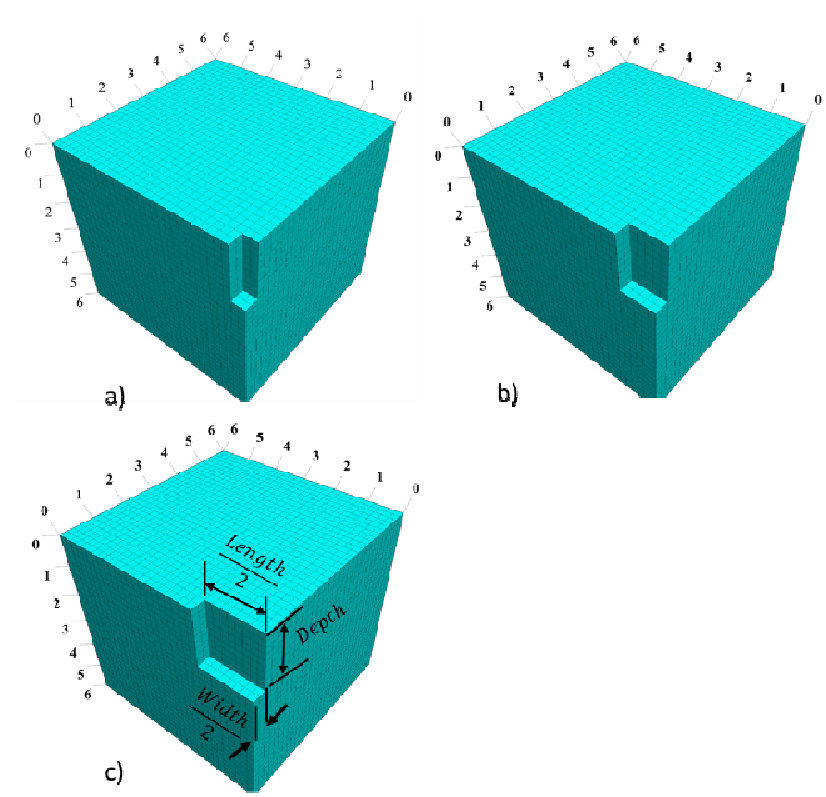

Fig. 7. Simulation of the unsupported vertical cut in FLAC3D; a) $0.8 \times 0.8 \times 1.8 \mathrm{~m}$, b) $0.8 \times 2.0 \times 1.8 \mathrm{~m}$, c) $0.8 \times 3.2 \times 1.8 \mathrm{~m}$.

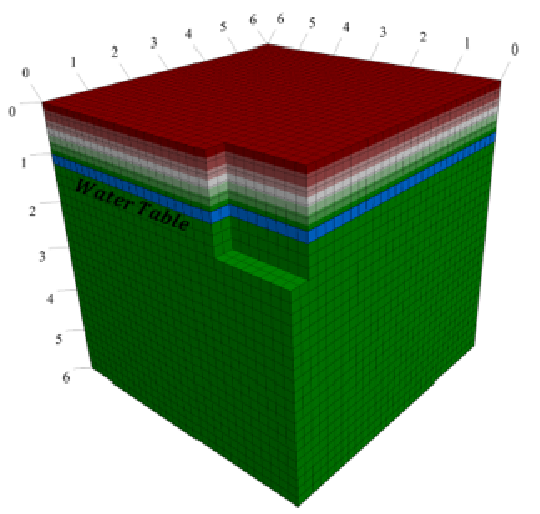

Cohesion $\mathrm{Pa}$

$8.5000 \mathrm{E}+03$

$8.0000 \mathrm{E}+03$

$7.5000 \mathrm{E}+03$

$7.0000 \mathrm{E}+03$

$6.5000 \mathrm{E}+03$

$6.0000 \mathrm{E}+03$

$5.5000 \mathrm{E}+03$

$5.0000 \mathrm{E}+03$

Fig. 8. Apparent cohesion profile in FLAC3D.

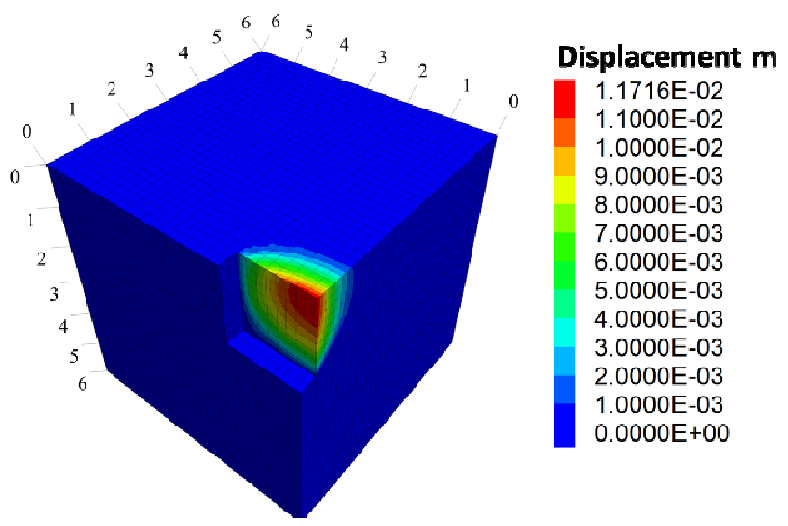

Fig. 9. Slip surface and displacement contour map in FLAC3D.
The variation of FOS with respect to the model length in $3 \mathrm{D}$ analyses is shown in Fig. 10 (excavation depth $=1.8 \mathrm{~m}$ ). The FOS was estimated to be 2.03 with the model length of $0.8 \mathrm{~m}$ and then gradually decreased up to 0.9 when the model length became $3.2 \mathrm{~m}$. This indicates that both $2 \mathrm{D}$ and $3 \mathrm{D}$ stability analyses produce the same FOS when the width of cross-section exceeds approximately $3 \mathrm{~m}$ for the investigated case.

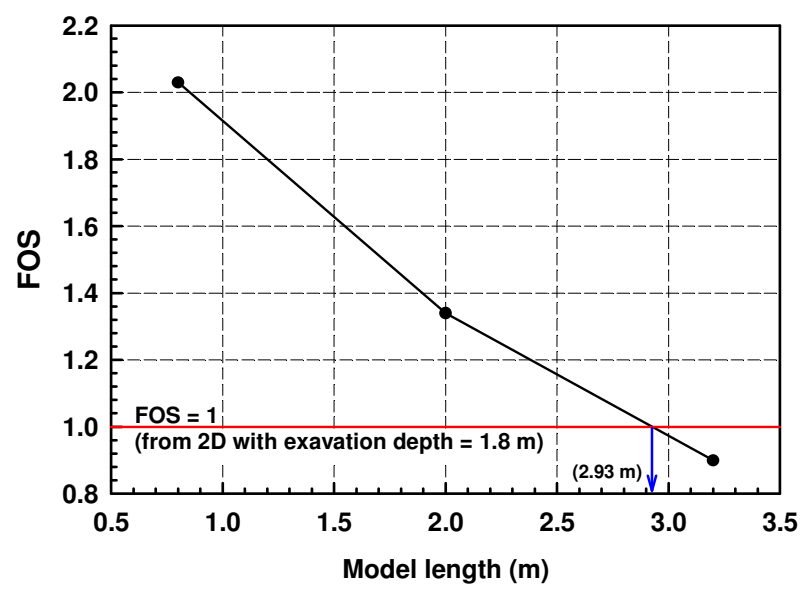

Fig. 10. Variation of FOS with respect to model length from 3D analyses compared with the critical height obtained from the 2D analysis (excavation depth $=1.8$ $\mathrm{m})$.

\section{SUMMARY AND CONCLUSION}

In this study, the influence of 3D effects on the critical height of an unsupported vertical cut excavated in a glacial till was investigated. For this, numerical analyses were conducted using both 2D (GeoStudio 2019 R2) and 3D (FLAC3D) models. The critical height was estimated to be $1.8 \mathrm{~m}$ from the $2 \mathrm{D}$ method. However, it was found that the critical height increases with a decreasing crosssection width using 3D analysis. The results showed that the influence of 3D effects is negligible when the width of an unsupported vertical cut exceeds approximately 3 $\mathrm{m}$ with the ground water table at $1 \mathrm{~m}$ below the surface. In other words, the stability of the cross-section of a vertical cut is not of concern if the width is 1.7 times greater than that of the critical height from the 2D method.

This study was performed with the ground water table at $1 \mathrm{~m}$ in a single soil type. More research is necessary with various levels of the ground water table in different types of soils.

\section{References}

1. D.E. Pufahl, D.G. Fredlund, H. Rahardjo, Can. Geotech. J. 20, 2, 228-241 (1983).

2. V. Whenham, M.D. Vos, C. Legrand, R. Charlier, J. Maertens, J.-C. Verbrugge. In Experimental Unsaturated Soil Mechanics, 495-501 (Springer Berlin Heidelberg, 2007). 
3. P. De Vita, A.C. Angrisani, E. Di Clemente, Ital. $j$. Eng. Geol. Environ. 2, 5-22 (2008).

4. S.K. Vanapalli, W.T. Oh, GeoCongress 2012, 25022511 (2012).

5. Infrastructure Health \& Safety Association (ISHA), Trenching safety (2010).

6. J. Hilf, An Investigation of pore-water pressure in compacted cohesive soils, PhD Dissertation, Technical Memorandum No. 654, U.S. Bureau of Reclamation, Denver, Co. (1956).

7. D.G. Fredlund, A. Xing, Can. Geotech. J. 31, 4, 521-532 (1994).

8. D.E Pufahl, D.G. Fredlund, H. Rahardjo, Can. Geotech. J. 20, 2, 228-241 (1981).

9. R. Adin, Estimating the critical height of unsupported trenches in unsaturated soils. Master's thesis, University of New Brunswick, Fredericton, Canada. 